\title{
Nanotechnology and Diagnostic Imaging: New Advances in Contrast Agent Technology
}

\author{
Joshua E. Rosen ${ }^{1}$, Serge Yoffe ${ }^{1}$, Ameena Meerasa ${ }^{1}$, Mohit Verma ${ }^{1}$ and Frank X. Gu ${ }^{1,2 *}$
}

${ }^{1}$ Department of Chemical Engineering, University of Waterloo, 200 University Ave. West, Waterloo, ON, N2L 3G1, Canada ${ }^{2}$ Waterloo Institute for Nanotechnology, University of Waterloo, 200 University Ave. West, Waterloo, ON, N2L 3G1, Canada

\begin{abstract}
Medical imaging technologies allow for the rapid diagnosis and evaluation of a wide range of pathologies. In order to increase their sensitivity and utility, many imaging technologies such as CT and MRI rely on intravenously administered contrast agents. While the current generation of contrast agents has enabled rapid diagnosis, they still suffer from many undesirable drawbacks including a lack of tissue specificity and systemic toxicity issues. Through advances made in nanotechnology and materials science, researchers are now creating a new generation of contrast agents that overcome many of these challenges, and are capable of providing more sensitive and specific information. In this review, we summarize the main classes of nanotechnology-based contrast agents for each of the major imaging technologies, and highlight progress in their development as well as the challenges to be addressed. We also review the relevant biological interactions that determine the in vivo fate of these contrast agents, and describe major themes in medical nanotechnology including stealth and targeting.
\end{abstract}

Keywords: Diagnostic imaging; Contrast agent; Nanotechnology; MRI; CT; PET; Multimodal imaging

\section{Introduction}

In recent years the field of nanomedicine, the development of medical technologies through nano-scale manipulations, has seen explosive growth. Progress has been made in areas such as targeted drug delivery [1], controlled drug release [2], tissue engineering [3], and in vitro diagnostics [4]. Through the benefits achieved at the nano-scale such as controlled distribution, enhanced sensitivity, and multifunctional materials, these innovations are starting to change the landscape of modern medicine. Nanotechnologies are also proving to be of immense utility in the vast and important field of diagnostic imaging.

Diagnostic imaging refers to a broad slew of technologies used to look inside of the body in order to diagnose various pathologies. These techniques are becoming an increasingly critical piece of the diagnostic portfolio available to physicians. Technologies such as Magnetic Resonance Imaging (MRI), Computed Tomography (CT), and Positron Emission Topography (PET) are becoming routine procedures in hospitals throughout the world due to the unparalleled look that they can provide into the body. In order to assist healthcare practitioners to visualize abnormalities on a diagnostic image, contrast agents, materials that interact with the incident radiation to produce visible changes on the resulting image, are often employed. Contrast agents are of great importance in diagnostic imaging as they can greatly increase the sensitivity of an imaging technique allowing the diagnosis of previously undetectable pathologies [5,6]. It is in this arena, the development of novel and improved contrast agents, that nanotechnology is making a significant impact to the field of diagnostic imaging. Through nano-scale manipulations researchers are continuing to improve upon the sensitivity, biocompatibility, and biodistribution profile of various contrast materials. Furthermore the use of nano-scale agents has opened up entirely new realms of imaging technologies and applications, such as fluorescence imaging.

In this review we will give an overview of the major technologies currently used for diagnostic imaging and the ways in which nanotechnology is being used to enhance these methods. We will also provide an overview of the various challenges that must be addressed when developing a new nanomaterial for medical use, and relevant information on biological interactions.

\section{Biological Interactions}

In order to appreciate the various challenges and design constraints that must be considered when designing a new nanoparticle based contrast agent, it is necessary to understand the basics mechanisms by which nanoparticles interact with the body. When a macromolecule such as a nanoparticle contrast agent is injected into the body, it is typically recognized as a foreign substance by the immune system, which causes the activation of various clearance mechanisms [7]. The body attempts to remove the offending material from circulation as rapidly as possible through various routes such as renal filtration, or through uptake by the various cells and components of the mononuclear phagocyte system (MPS) found in the liver, spleen, and lymph nodes [8-10]. Thus a significant design challenge with nanoparticle systems involves modifying them to achieve prolonged circulation time, while still maintaining their biocompatibility and eventual ability to be broken down and removed form circulation once they have accomplished their clinical goal [8]. The primary factors governing how nanomaterials interact with biological systems are their size and surface properties.

\section{Immune system and clearance routes}

A key host defense system involved in the clearance of nanoparticles is the immune system, specifically the elements of the MPS and the complement system. The MPS refers to the professional phagocytes of

*Corresponding author: Frank X. Gu, Waterloo Institute for Nanotechnology, University of Waterloo, 200 University Ave. West, Waterloo, ON, N2L 3G1, Canada, Tel: (519) 888-4567 Fax: +1 519888 4347; Email: frank.gu@uwaterloo.ca

Received September 08, 2011; Accepted October 19, 2011; Published October 21, 2011

Citation: Rosen JE, Yoffe S, Meerasa A, Verma M, Gu FX (2011) Nanotechnology and Diagnostic Imaging: New Advances in Contrast Agent Technology. J Nanomedic Nanotechnol 2:115. doi:10.4172/2157-7439.1000115

Copyright: @ 2011 Rosen JE, et al. This is an open-access article distributed unde the terms of the Creative Commons Attribution License, which permits unrestricted use, distribution, and reproduction in any medium, provided the original author and source are credited. 
the immune system responsible for phagocytising and clearing foreign material [7]. The complement system is a family of blood proteins that become activated in the presence of foreign materials. They initiate a cascade that can result in opsonization, the adsorption of proteins on the surface, of nanoparticles, which marks them for uptake and clearance by the cells of the MPS $[7,8,11,12]$. Thus it is desirable for nanoparticles to maintain a surface that prevents opsonization of complement proteins and antibodies, which will prolong the particles circulation time. Previously, it has been found that hydrophobic and highly charged surfaces are the most prone to opsonization, while hydrophilic and neutral surfaces are not, and are thus more "stealthy" $[10,11,13]$. Furthermore, particle size has been found to play a role as well, with larger particles experiencing more rapid clearance than smaller particles $[8,12]$. However one must ensure that the particles are not too small, as materials less than $5.5 \mathrm{~nm}$ in hydrodynamic size tend to experience rapid clearance by the kidneys [14]. We thus are presented with a complex optimization problem where one must balance the competing concerns of achieving long circulation time with the need to achieve high signal strength (often achieved through using larger particles). A particles size also impacts its ability to leave the circulation and thus enter various types of tissues such as tumors. Furthermore one must still keep in mind that after its useful lifetime, the nanoparticle must be able to degrade or be otherwise removed from the body to prevent any long-term toxicity. Particle size is typically determined during the synthesis of the nanoparticle material, and can not be readily decreased afterwards, however there are a variety of strategies that one can employ in order to modify the surface properties of a particular nanoparticle to decrease opsonization.

\section{Coating agents}

As discussed previously, nanoparticles surface properties can heavily dictate their interaction with the host. Many of the nanomaterials used as contrast agents including iron oxide, silica, quantum dots, and some polymers, have surface characteristics such as high charge, hydrophobicity, or inherent toxicity that must be masked from their biological environment. For example, the native surface charge of silica nanoparticles is quite negative due to its low isoelectric point $(\mathrm{pH}=2)$. It would thus experience rapid adsorption of positively charged proteins in a biological environment, resulting in fast clearance. Coating agents are also necessary to stabilize some particles against aggregation. Iron oxide nanoparticles for example are not colloidaly stable under physiological conditions and thus must be coated with a stabilizing agent to impart the necessary level of colloidal stability [15].

There are various coating materials that are used to impart biocompatibility, colloidal stability, and stealth properties and the choice of which one to use is related to both the nanoparticle system involved and its intended use. One common class of compounds are synthetic and natural hydrophilic polymers such as poly(ethylene glycol) (PEG) [16,17], poly(vinyl alcohol) (PVA) [18-20], poly(Llysine) (PLL) [21], poly(acrylic acid) (PAA) [22], dextran [23-27], alginate [28-30], chitosan [31-33], starch [34-36], and gum Arabic [3739] to name a few. These materials are effective at creating a neutral and hydrophilic surface that can resist protein adsorption, however they also come with the drawback of increasing a particle's hydrodynamic size. Small molecules can also be used to provide effective surface coatings, such as thiol-containing molecules for quantum dots, or other neutral or zwitterionic molecules on silica and other materials [40]. These materials result in a much smaller increase of the particles hydrodynamic size, but might present other drawbacks such as less effective stabilization or a less stable coating. When selecting a surface coating agent, one must also consider the available chemical functional groups it will present at the particles surface, as this will be important for the conjugation of other molecules such as external drug payloads or targeting ligands.

\section{Targeting}

Targeting, the ability for a nanoparticle to identify a tissue of interest and selectively accumulate within it, is perhaps one of the most often publicized promises of nanotechnology. By selectively targeting cancerous tissues, toxic chemotherapeutic agents can be delivered to tumors at much higher doses while mitigating the unpleasant side effects often associated with chemotherapy. Through targeting, contrast agents can provide much more useful and detailed information about precise differences in tissue types and margins, which can help identify malignant or abnormal tissues much earlier than a systemic contrast agent. By targeting contrast materials specifically to a tissue of interest, it becomes possible to lower the dose given, thus saving expense and reducing exposure to potentially toxic materials. Furthermore, the signal to noise ratio of the resulting image can be improved, as there will be less contrast agent "floating free" in the body.

Generally targeting methods fall into two different categories: passive targeting or active targeting. Passive targeting relies on the various physiological abnormalities or phenomena that are present in a diseased condition in order to provide selective accumulation. Perhaps the most well known example of this type of targeting is the enhanced permeability and retention (EPR) effect seen in solid tumors. Due to a combination of poorly formed and permeable blood vessels, and a poor lymphatic drainage system, macromolecules tend to selectively enter and accumulate in tumors [41-43]. Another example of passive targeting can be seen with the commercial liver contrast agent Feridex, an iron oxide based material which is taken up by healthy liver and spleen tissues, but not cancerous tissues, thus providing enhanced contrast for liver and spleen imaging [6]. Active targeting refers to situations where a targeting ligand, a molecule that recognizes and binds to a specific biomarker, is conjugated to the surface of a nanomaterial. Generally the biomarker that is recognized is one that is expressed either exclusively, or in much higher numbers on the tissue of interest than in normal tissues. Thus in addition to any native passive targeting effects, an extra layer of specificity is added. Furthermore, due to the specific binding of the material to a cellular surface receptor, a receptor-mediated endocytosis process is often initiated, resulting in the internalization and intracellular accumulation of the contrast agent [44-46]. Active targeting has been explored for imaging a number of conditions including cancer (Figure 1) [43,47-49], myocardial infarction [50], and inflamed endothelial cells [51] (possibly indicating atherosclerosis) to name a few. The topic of targeting is quite broad and we will not cover it in any more detail in this review. Please see references $[1,41,43,52-54]$ for more in-depth discussions of both active and passive targeting for various conditions.

\section{Magnetic resonance imaging}

Magnetic resonance imaging (MRI) is a powerful and highly useful tool in soft-tissue medical imaging and diagnostics. It possesses high temporal and spatial resolution, and is considered quite safe and non-invasive due to the absence of ionizing radiation [23]. MRI is highly effective at imaging tumours and is often used in conjunction with targeted cancer therapy to achieve real-time monitoring of drug delivery and accumulation in the affected area $[22,55,56]$. In addition, it can be used to image and track individual cells in vivo [57,58]. 


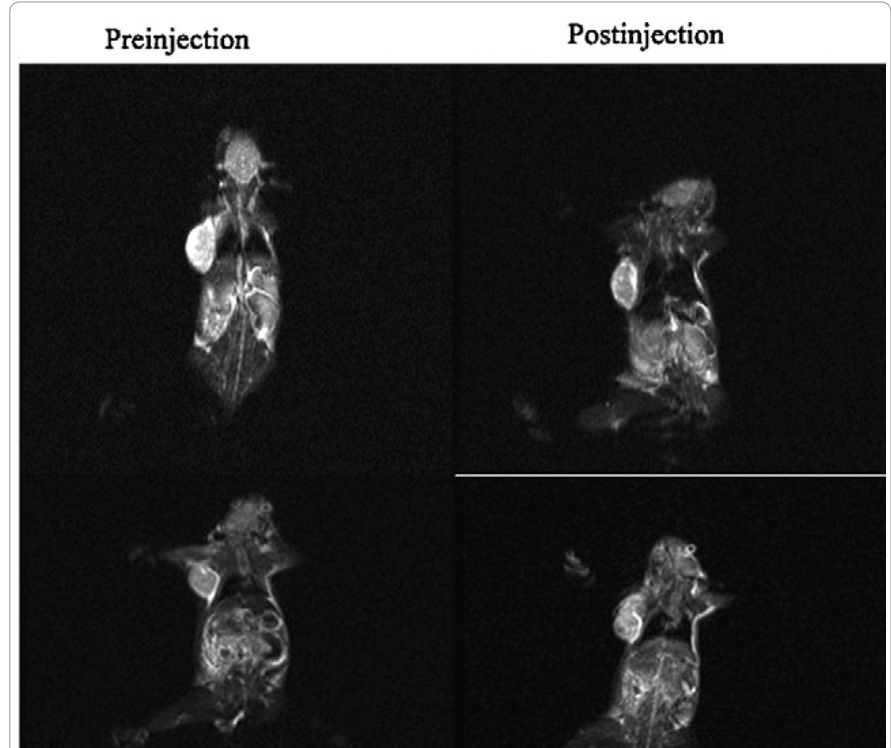

Figure 1: MRI image of a subcutaneous tumor formed from KB cells in a mouse model both before (left) and after (right) injection of non-targeted SPIONs (top) or SPIONs targeted to folate receptors by conjugating folic acid ligands to their surface (bottom). Note how the tumor has significant signal intensity change $(27.23 \%)$ when targeted nanoparticles are used, but negligible change $(1.25 \%)$ when the un-targeted particles are used. Folate receptors are overexpressed on many cancers, including KB cells, and as such are often probed with active targeting techniques. Reprinted with permission from Fan, C. et al. (2011) Tumor selectivity of stealth multi-functionalized superparamagnetic iron oxide nanoparticles. Int J Pharm 404: 180-190. [49]

MRI works by applying a strong external magnetic field to interact with the abundant water protons that are found in soft tissue. An applied magnetic field causes the magnetic moments in the protons to align in the direction of the field. A radiofrequency (RF) pulse is sent through the tissue, which causes the protons to precess in a specific direction at a certain frequency, specific to the type of tissue the proton happens to reside in. Upon removal of the RF pulse, the protons return to their ground state, a process termed relaxation. The relaxation time (time to return to ground state) is made up of two components corresponding to the decomposition of the angular momentum vectors of the protons: longitudinal relaxation time, $\mathrm{T}_{1}$, and transverse relaxation time, $\mathrm{T}_{2}$. Through computer-aided reconstruction of the detected relaxation signals, the tissue-dependent variation in the $T_{1}$ and $\mathrm{T}_{2}$ values leads to contrast differences in the resulting composite images. A greater difference in relaxation time between two tissues will produce greater contrast on the MRI image. For many applications, such as tumour diagnosis and cellular imaging and tracking, it is crucial to improve the imaging capabilities of MRI by using contrastenhancing agent. Contrast agents produce a more pronounced image by altering the relaxation times of water protons around them [59]. Thus by accumulating in specific tissues, the contrast agent will further enhance the visibility of various structures and lesions on an MR image.

\section{Contrast agents for MRI}

Currently, many clinically used contrast agents are based on Gadolinium (III) ions. Gadolinium ions are strongly paramagnetic; they have a large magnetic moment due to their unpaired electrons [60]. These agents provide positive contrast, bright spots, on $\mathrm{T}_{1}$ weighted images. Although the ions themselves are highly toxic, the proper choice of ligands can produce gadolinium chelates that are nontoxic and highly stable in the body during the period of administration
[61]. One of the most common chelates is Gd-DTPA (DTPA = diethylenetriamine pentaacetic acid), which has been used clinically as the contrast agent Magnevist ${ }^{\circ}$ [60]. Several other types of chelates are used regularly in clinic with different biodistribution profiles, which can favour their use for specific applications such as liver imaging $[62,63]$. Gadolinium chelates have also been used in targeted drug delivery. For example, Park et al. [64] conjugated the peptide RGD to Gd-DOTA (DOTA = tetraazacyclododecane tetraacetic acid) to obtain an MRI contrast agent with tumor targeting capability.

Gadolinium has also been employed in various nanoparticle formulations to create enhanced MRI contrast agents. These formulations show greater sensitivity at high magnetic fields as they can concentrate a greater number of gadolinium ions in the tissue of interest [63]. Gadolinium ions can be incorporated into various types of nano-scale scaffolds including organics such as polymers $[65,66]$, and liposomes [67], as well as inorganics such as carbon nanotubes and silica nanoparticles $[68,69]$. Nanoparticles of gadolinium oxide are also promising candidates for use in future paramagnetic contrast agent formulations [68].

Another commonly used and clinically relevant contrast agent is the superparamagnetic iron oxide nanoparticle (SPION). SPIONs improve imaging by reducing the $\mathrm{T}_{2}$ relaxation time of nearby water protons, producing visible signal voids - seen as dark spots - on $\mathrm{T}_{2}$-weighted images [59]. The superparamagnetic property of SPIONs is one of their most important characteristics for in vivo imaging applications, which only occurs when the individual particles are below $20 \mathrm{~nm}$ in size [70] This property is absent in bulk iron oxide, which is a ferromagnetic (permanently magnetized) material. Superparamagnetism is similar to the paramagnetism exhibited by materials such as gadolinium; the material only shows a net magnetization when placed in an external magnetic field. However in contrast to paramagnetic materials, superparamagnetic materials retain zero net magnetization upon removal of the external field (i.e. they exhibit no hysteresis) $[23,70,71]$. The absence of any remnant magnetization significantly reduces the magnetic dipole-dipole interactions between SPIONs and thus helps to keep them from agglomerating. When a strong magnetic field is applied, however, SPIONs exhibit a stronger magnetic response than most paramagnetic materials [72], making them highly useful for imaging applications. The degree of MRI signal interference, and thus the contrast enhancement, provided by SPIONs is proportional to their saturation magnetization $\left(\mathrm{M}_{\mathrm{s}}\right)$ value, the point at which all the individual magnetic moments in a sample are uniformly aligned. The various phase of iron oxide exhibit different $M_{s}$ values Bulk magnetite has a higher $M_{s}(92 \mathrm{emu} / \mathrm{g}$ at $300 \mathrm{~K})$ than that of maghemite $(76$ $\mathrm{emu} / \mathrm{g}$ ) [73], making the former a somewhat better choice for imaging applications. In practice, the $\mathrm{M}_{\mathrm{s}}$ of SPIONs rarely reaches that of the bulk because it depends strongly on their size and morphology in addition to the manner in which they were synthesized. Variables such as reaction temperature, $\mathrm{pH}$ and reactant concentration all have an effect on the magnetic properties of SPIONs [71].

Although iron oxide is considered non-toxic and is eventually metabolized by the body into haemoglobin [44,74], high doses of iron increase the probability of toxicity [23]. Therefore, for in vivo work, it is important to use SPIONs with high saturation magnetization values to minimize iron loading.

\section{Computed tomography scanning}

Computed tomography (CT) scanning is an X-ray based imaging technology that can create detailed cross-sectional images of many 
Citation: Rosen JE, Yoffe S, Meerasa A, Verma M, Gu FX (2011) Nanotechnology and Diagnostic Imaging: New Advances in Contrast Agent Technology. J Nanomedic Nanotechnol 2:115. doi:10.4172/2157-7439.1000115

different tissue types. It is typically accomplished by taking multiple $\mathrm{X}$-rays from different angles to form image "slices" which can then be composited together to form a detailed set of cross-sectional images. It is commonly used for imaging of the pelvis, head, abdomen and chest. Currently, iodine or gadolinium-based molecules are used as contrast agents for CT scans; however, they suffer from many problems including a nonspecific biodistribution, short circulation half lives $(<10 \mathrm{~min}$ for conventional iodinated compounds) [75], a requirement for catheterization, slight renal toxicity and poor contrast in larger patients [76]. In recent years, various nanomaterial-based contrast agents have been developed that are able to overcome many of shortcomings of traditional CT contrast agents. These include bismuth sulphide $\left(\mathrm{Bi}_{2} \mathrm{~S}_{3}\right)$ nanoparticles [75], iodinated nanoparticles, gold nanoparticles $[37,76,77]$, as well as polymeric and liposomal carriers for conventional iodine-based contrast agents [78-82]

\section{Nanoparticles for CT}

Polymer-coated $\mathrm{Bi}_{2} \mathrm{~S}_{3}$ nanoparticles are a promising new class of contrast agent that has been developed for use with CT imaging. These nanoparticles are typically synthesized in a two-step process. The $\mathrm{Bi}_{2} \mathrm{~S}_{3}$ cores are created through precipitation of bismuth citrate and sodium sulfide, and are then coated with a polymer such as polyvinylpyrrolidone (PVP) to impart colloidal stability, biocompatibility, and the ability to evade the MPS [75]. These particles exhibited a 5-fold increase in X-ray absorption compared to iodine-based contrast agents and displayed much longer circulation half lives ( $>2$ hours), which opens up the possibility of using these particles as targeted contrast agents [75]. The clinical utility of these particles was demonstrated in vivo in a mouse model, where it was shown that these particles were an effective contrast enhancer for imaging the liver, lymph nodes and vasculature [75]. Potential problems with these contrast agents include difficulty in controlling the shape of the $\mathrm{Bi}_{2} \mathrm{~S}_{3}$ nanoparticles and a comparative lack of methods to modify their surface [77].

Gold nanoparticles are another class of CT contrast agents that has been studied to a much greater degree than the aforementioned $\mathrm{Bi}_{2} \mathrm{~S}_{3}$ nanoparticles. Gold nanoparticles are excellent CT contrast agents due to their increased X-ray absorption (2.7-5.7 times) compared to iodine and their prolonged blood circulation time (4 hours in rats compared to 10 minutes for iodine) [76,77]. This longer circulation time is a synergistic effect resulting from the biocompatible polymer coating the particles [77] and their increased size, which helps to reduce the rapid renal clearance and extravasation exhibited by smaller contrast agents [76]. Another major advantage to utilizing gold-based contrast agents is that they can be best imaged with X-ray energies of $80-100 \mathrm{keV}$. This energy range experiences reduced absorption by both soft tissue and bone, meaning that patients can be subjected to lower doses of radiation as a result [76]. Commercially available $1.6 \mathrm{~nm}$ gold nanoparticles have been used in vivo with a mouse model of mammary carcinoma. These small particles displayed low accumulation in the liver and spleen, and allowed for very clear imaging of the neovasculature, which led to efficient tumor detection on CT scans (Figure 2) [76]. Scans taken with the iodine-based contrast agent did not allow for such clear tumor detection. In a separate study, $30 \mathrm{~nm}$ gold nanoparticles coated with PEG were used in a rodent model and shown to be effective blood pool and hepatoma imaging agents [77]. In both of these studies, the particles were found to exhibit very low in vivo toxicity.

While gold and $\mathrm{Bi}_{2} \mathrm{~S}_{3}$ nanoparticles employ a slew of new materials to create contrast, other emerging CT contrast agents rely on enhancements to older materials. Iodine, in a vast array of formulations, is by far the most commonly used CT contrast agent today [83]. While it possesses excellent $\mathrm{x}$-ray attenuation capabilities, current iodine based contrast agents still suffer from a lack of tissue specificity and short circulation time. In order to overcome these limitations, iodine is being incorporated into various engineered nanostructures. Some of the various strategies that have been employed include using nanoscale coordination polymers capable of carrying a large iodine payload [78], encapsulating the iodine in liposomes (Figure 3) [79,84-86], using iodinated polymeric nanoparticles [80-82], and incorporating iodine into various other nanostructure [87-89]. These strategies lead to longer circulation times compared to conventional CT imaging agents, which can allow for the development of targeted imaging agents as well as CT contrast agents capable of molecular imaging [90]. By increasing the local concentration of iodine in a tissue through these strategies, image contrast can be significantly improved [83].

\section{Positron emission topography scanning}

Positron emission topography (PET) scanning is another
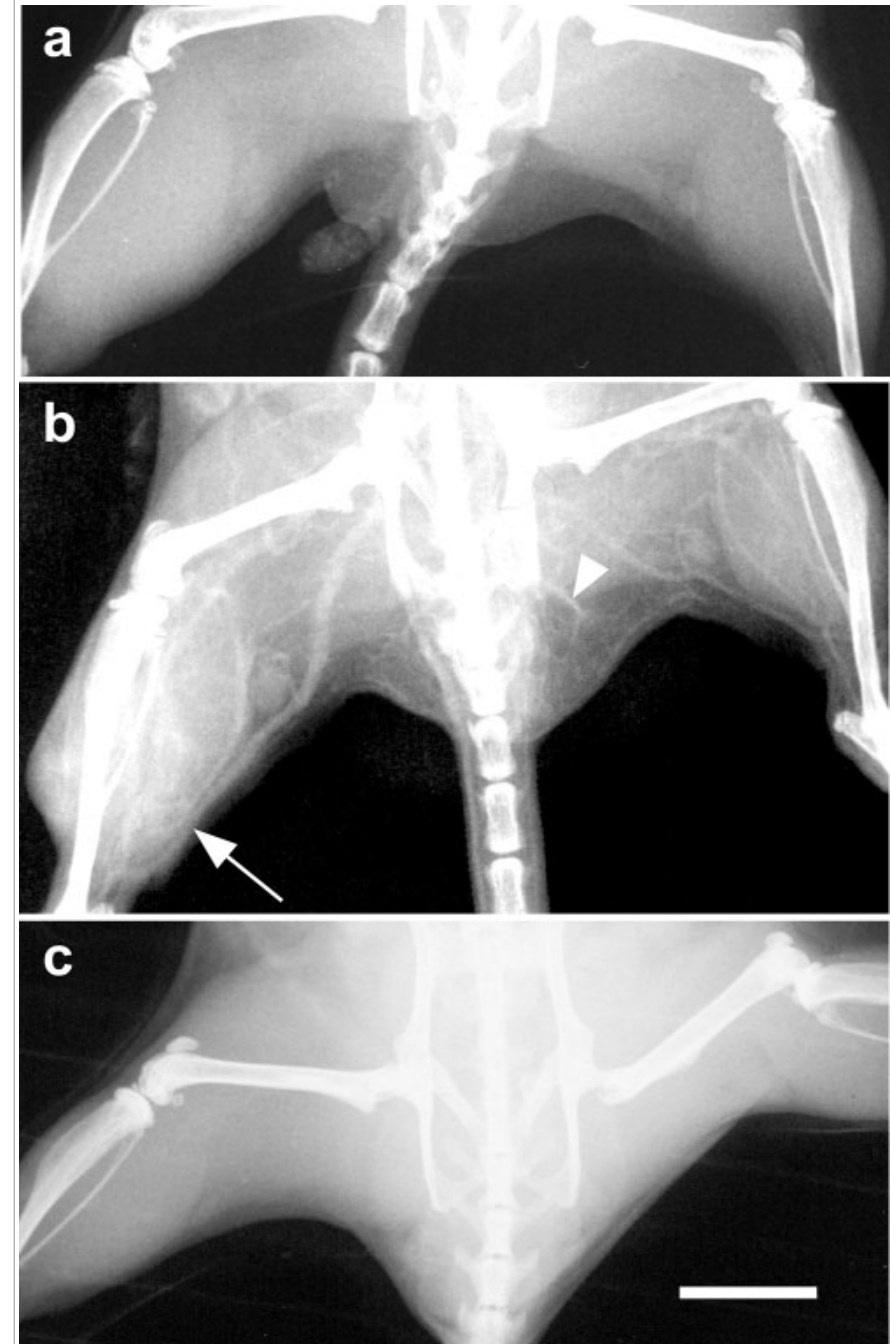

Figure 2: CT image of a mouse before administration (a) and 2 minutes after administration of gold nanoparticles (b) and commercial iodinated contrast agent Omnipaque ${ }^{\circledR}$. It is readily apparent that the gold nanoparticles allow clear visualization of the vasculature structure revealing increased vascularization in the left leg (arrow) indicative of a tumor. Scale bar $=5 \mathrm{~mm}$. Reprinted with permission from Hainfeld, JF. et al. (2006) Gold nanoparticles: a new X-ray contrast agent. Br J Radiol 79: 248-253. [76]. 


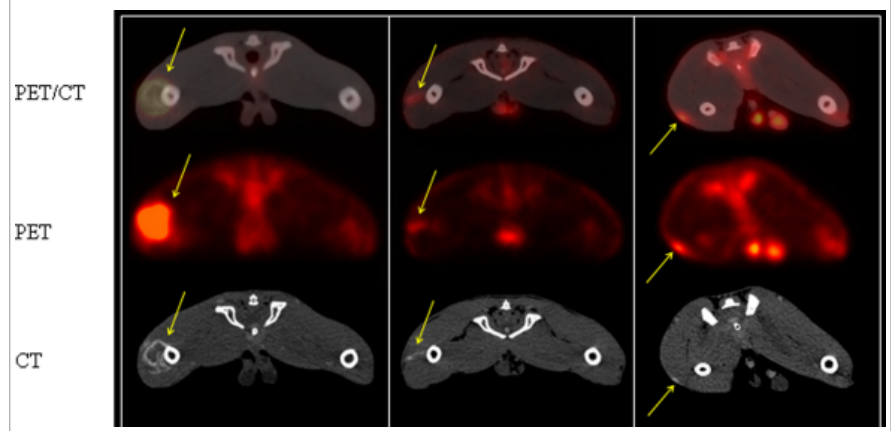

Figure 3: CT and PET images of primary tumors in a rabbit model acquired using a contrast agent comprising a liposome encapsulating the iodine-based contrast agent Omnipaque ${ }^{\circledR}$ (iohexol) and the MRI contrast agent Prohance ${ }^{\circledR}$ (gadoteridol). In this study the liposomal contrast agent was injected 7 days after tumor inoculation. 5 days later, an injection of the radionucleide ${ }^{18} \mathrm{~F}-\mathrm{FDG}$ was administered and 1 hour later the PET and CT images were acquired. Effective visualization of the tumors (indicated by the arrow) on the CT image was confirmed with the overlaid PET scan. Reprinted with permission from Zheng, J. et al. (2010) Liposome contrast agent for CT-based detection and localization of neoplastic and inflammatory lesions in rabbits: validation with FDG-PET and histology. Contrast Media Mol Imaging 5: 147-154. [86].

commonly used diagnostic technique in modern medicine. In contrast to techniques such as MRI, CT and X-ray, which tend to provide information of a structural nature, PET provides functional information about the body. PET is also a quantitative technique, meaning that it can be used to measure the amount of contrast agent present in a particular organ or tissue over a period of time [90]. Using PET, doctors can examine properties such as blood flow, glucose metabolism and oxygen use. PET scans generally have increased tissue penetration compared to many other imaging techniques such as optical, fluorescence and ultrasound imaging [90,91]. Due to the fact that PET scans do not provide good structural resolution, PET is often used in concert with other imaging techniques (commonly CT) in order to provide both structural and functional information about the body. PET scans utilize radiotracers with short half lives such as ${ }^{11} \mathrm{C},{ }^{13} \mathrm{~N}$, ${ }^{15} \mathrm{O},{ }^{18} \mathrm{~F}$ and ${ }^{64} \mathrm{Cu}$ incorporated into biomolecules in order to measure the distribution and metabolism of said biomolecules throughout the body. For example, fluorodeoxygluocose is a radiotracer used to measure glucose metabolism in a PET scan. These types of radiolabels are often employed to study nanoparticle pharmacokinetics [90]. PET techniques provide an interesting tool for nanomaterials researchers who are interested in tracking the biodistribution of a new nanomaterial formulation. For example, single-walled nanotubes have been radiolabeled in order to track their biodistribution in vivo $[90,92,93]$. Thus it is readily apparent that nanomaterials can be a valuable tool for PET technology, acting as carriers for radiotracer molecules while performing other tasks such as drug delivery. One must keep in mind however that PET detects the radiolabel, rather than the nanoparticle itself. It is thus possible to obtain inaccurate results if the two compounds dissociate from one another after administration [90].

As mentioned, a common trend in modern medicine is to combine PET imaging with another imaging technique in order to create a composite image providing both structural and functional information. Nanoparticles serve as ideal platforms for so-called "multimodal imaging" contrast agents due to their large surface area, which allows various imaging or therapeutic ligands to be conjugated to them [90]. Chelated metals such as ${ }^{64} \mathrm{Cu}$ are commonly used radiolabeling agents for macromolecules; however, they suffer from some drawbacks due to their large size and the charged nature of the chelates, which could theoretically influence the macromolecule's structure and therefore its pharmacokinetic properties [91]. As such, work is being done to develop effective radiolabels utilizing other radionuclides such as ${ }^{18} \mathrm{~F}$, to avoid influencing the structure of the macromolecule being studied [91]. Nevertheless, ${ }^{64} \mathrm{Cu}$ has still been used for the in vivo tracking of the biodistribution of single walled nanotubes in a mouse model [92]. Overall, PET technology is a very useful tool in both diagnostics and research. The diagnostic utility of PET can be greatly improved by utilizing new nanomaterials to develop more effective multimodal contrast agents capable of providing simultaneous structural and functional data.

\section{Fluorescence imaging}

Organic fluorophores and fluorescent proteins have long been used in biological research to study various cellular and molecular processes both in vitro and in small animal models in a sensitive and non-invasive manner [94]. These small chemical entities can be incorporated into various macromolecules and used with techniques such as confocal microscopy and flow cytometry to study the in vitro interaction of these macromolecules with cells (e.g. internalization) as well as their in vivo biodistribution and fate. Florescent molecules are often used for cell labelling and cell tracking; they are also heavily employed in nanomedical research to examine cell uptake and retention of nanoparticles and to track the biodistribution of nanoparticles in animal models. Currently, there are many limitations to fluorescence based imaging with conventional fluorophores: poor skin/tissue penetration, wide emission and absorption bands, poor signal strength, short imaging times in vivo, and high susceptibility to photobleaching (the eventual destruction of the fluorophore due to the stimulating light energy) $[95,96]$. This has resulted in the somewhat limited use of fluorescence imaging techniques in vivo, as well as their general exclusion from clinical use.

New advances in fluorescent nanomaterials are beginning to overcome many of the problems associated with traditional fluorophores and are starting to open up the possibility of utilizing fluorescence imaging techniques to diagnose a wide range of diseases and to gain even more insight into disease progression on systemic, cellular and molecular levels. Additionally, fluorescent tagging is a commonly used method with all types of nanomaterials (e.g. polymer drug delivery vehicles, iron oxide MRI contrast agents, etc.) to ascertain information about their biodistribution, cellular uptake, and tumoral accumulation mechanisms.

\section{Semiconductor quantum dots}

Semiconductor quantum dots (QDs) are nanometer-sized particles, generally made from combinations of heavy metals (CdSe, $\mathrm{CdTe}$, InP, InAs, etc.), with unique optical properties that make them ideal candidates to replace conventional organic fluorophores in fluorescence based imaging [97]. Unlike organic fluorophores, QDs are able to absorb light across a large spectral range, but their emission spectrum remains narrow, meaning that they always emit a well-defined wavelength of light no matter what their input wavelength is $[97,98]$. Tuning the size and composition of the QD allows for extremely fine control of the emission wavelength of the particles [98]. These properties allow QD fluorescent probes to be used for optical multiplexing where different probes can all be illuminated with the same light source but are able to have different colour emissions [98] Additionally, QDs are extremely bright, possess high photo-stability, 
and their large molar extinction coefficients mean that they can be more effectively utilized for in vivo imaging because they are not as sensitive to tissue depth [97]. QDs have been used to label cellular components, track cell movement and differentiation, image vasculature and lymph nodes and visualize the tissue distribution of nanomaterials (Figure 4) [97,99-101]. One of the major drawbacks of QD fluorescent tags is that there are serious concerns about possible toxic side effects; QDs are generally made of heavy metals such as Cd, which is known to have toxic effects in its free form $\left(\mathrm{Cd}^{2+}\right)$ [95]. In addition, the mechanisms by which QDs, whose sizes are above the renal excretion threshold (5.5 $\mathrm{nm}$ hydrodynamic diameter) [14], are degraded in vivo are not well understood, leading to the concern that they can accumulate in the organs of the MPS for extended periods of time causing potentially harmful side effects [95]. Some studies have indicated that if properly coated, QDs can be retained in the body for over 2 years post injection while still preserving their fluorescent properties [101].

\section{Encapsulated fluorophores}

In addition to QDs, nano-scale fluorescent materials can also be created by encapsulating traditional organic fluorophores within a nanoparticle carrier. This often enhances the properties of the fluorophore by increasing the signal strength and therefore the sensitivity of an assay due to the large number of dye molecules entrapped. Encapsulation also improves resistance to photobleaching compared to the un-encapsulated dyes and allow for more control over the biodistribution and clearance rates compared to small molecule organic fluorophores $[102,103]$. One of the most common methods of encapsulation involves the entrapment of organic fluorophores within silica nanoparticles [102]. These particles can be synthesized via a variety of routes, however it is often a challenge to entrap hydrophobic dye molecules within the hydrophilic environment of a silica nanoparticles. This can be accomplished by covalently linking the dye molecule to a silica precursor, which can then be utilized in the synthesis of the silica nanoparticles through the classic Stöber synthesis method [102,104]. This same strategy can also be used to create more highly structured core-shell particles as well [104-106]. When using polar dye molecules, it is also possible to use the micro-emulsion method of synthesis; the particles are created in the water droplets of water in oil microemulsion and the dye is physically entrapped inside of the particles [102]. There are various methods available for entrapping hydrophobic dyes using the micro-emulsion method, which are intriguing given that this method is able to produce more controlled and monodisperse particles compared to the classic Stöber synthesis [102]. Silica based systems are particularly intriguing due to their low toxicity, and high potential for further surface modification [102,103]. Dye molecules can also be encapsulated within polymer particles through a variety of methods, however they tend to suffer from more issues related to dye leakage and aggregation than silica nanoparticles [102,103].

\section{Discussion and Future Perspectives}

Diagnostic imaging, along with traditional contrast agents, has given us the power to diagnose a vast array of conditions in a minimally invasive manner. Despite this great success, the current generation of contrast agents still experience many issues preventing them from achieving even higher levels of clinical success. One of the greatest limitations of current contrast technology is its lack of tissue specificity. The majority of current agents, such as various formulations of iodine or gadolinium for CT and MRI respectively, will diffuse out of the vasculature into a variety of tissue types making it harder to observe abnormalities such as a plaque or tumor. Nanotechnology offers the possibility of a more tightly controlled bio-distribution profile by allowing for both active and passive targeting techniques to be employed. By confining a contrast agent to one particular tissue type (e.g. a tumor but not surrounding healthy tissue) the diagnostic capabilities of the various imaging techniques can be greatly improved. In general the large surface area present on most nanomaterials also allows for modifications to optimize the pharmacokinetic and clearance profiles of engineered nanomaterials [107]. By employing various types of surface coatings such as dextran or poly (ethylene glycol), one can modify the interactions between the nanoparticle and various biological systems resulting in different pharmacokinetic properties.

In addition to issues of specificity, many of our currently used contrast materials themselves have distinct disadvantages associated with them, which limit their use in certain situations or patient populations. For example, several concerns related to the long-term toxicity of gadolinium-based agents used in MRI have been raised. There are serious contraindications against the administration of gadolinium to patients with impaired renal function due to its association with the development of nephrogenic systemic fibrosis in these patient populations [108]. The availability of iron oxide-based contrast agents provides an alternative material for use in these highrisk populations. Having a wider range of materials available for each diagnostic technique will allow for the expanded use of diagnostic imaging techniques in patient populations and situations that current materials either perform poorly in or cannot be used outright.

Another limitation of current contrast agents is the amount of information that they can provide. The various imaging techniques each have their own strengths and limitations: MRI provides good spatial resolution in soft tissues but suffers from low sensitivity; CT provides excellent structural imaging but little functional information; PET/SPECT allows for quantitative evaluation of functional processes but suffers from poor spatial resolution; the incredible sensitivity of optical/fluorescence imaging is limited by poor tissue penetration. In order to maximize the amount of information a diagnostic image can provide, it would be ideal to combine multiple techniques to simultaneously acquire different types of information [83]. So called multimodal imaging involves the use of two or more imaging techniques at once in order to ascertain different types of information that can be used to form more accurate and detailed diagnoses. Currently, one commonly used example of multimodal imaging is combined CT/ PET scanning; the CT scan provides detailed anatomical/structural information upon which the functional PET data can be overlaid. By incorporating a PET radiotracer into a CT contrast agent, it is possible to obtain both types of information and overlay them in order to diagnose various health problems. Due to their large surface area,

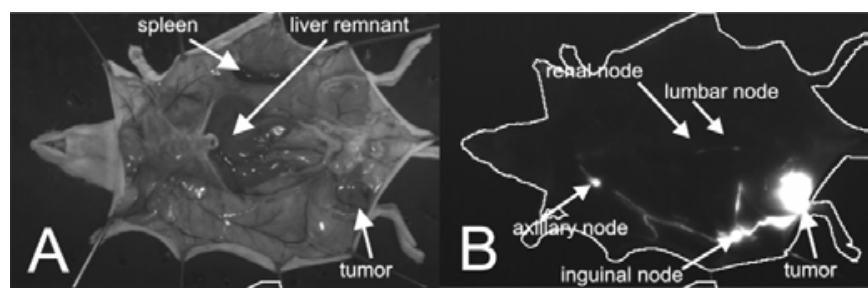

Figure 4: Visible light $(A)$ and fluorescence $(B, 655 \mathrm{~nm})$ images of a mouse bearing a subcutaneous M21 melanoma tumor 45minutes after injection of carboxy-PEG coated QD's directly into the tumor. The image highlights how the sentinel lymph nodes that the tumor drains into can be readily identified. Reprinted with permission from Ballou, B. et al. (2007) Sentinel Lymph Node Imaging Using Quantum Dots in Mouse Tumor Models. Bioconjug Chem 18: 389-396. Copyright 2011 American Chemical Society. [101] 
nanoparticles are ideal candidates for developing multimodal imaging contrast agents. The ample surface area allows for the conjugation of large numbers of secondary contrast molecules or targeting moieties. For example, fluorescent molecules can be conjugated to the surface of iron oxide nanoparticles for dual MRI and fluorescence imaging, or PET radiotracers can be conjugated to the surface of gold nanoparticles to make even more effective CT/PET contrast agents (Figure 5). Multimodal imaging techniques have the potential to greatly increase the ability of physicians to diagnose a variety of conditions by allowing for the efficient integration of various types of diagnostic information.

Building on the theme of multimodal imaging, nanoparticles are prime candidates for so-called "theranostic" applications; the combination of therapeutic and diagnostic properties into a single formulation $[109,110]$. Using theranostic technologies, researchers hope to achieve more direct and real-time monitoring of treatment processes, more detailed information on biodistribution and pharmacokinetics during evaluations of new drugs, and more nuanced control over the treatment process in response to changing symptoms and disease progression $[83,111]$. There are also hopes for improved clinical efficiency through reduced need to schedule separate diagnostic and treatment procedures [112]. For example magnetic nanoparticles are often considered for theranostic applications. Their superparamagnetic nature allows for MRI imaging, while pharmaceutical agents can be coupled to their surface. Furthermore the particles themselves can be used for therapy through techniques such as magnetic hyperthermia [113]. This field is still in its infancy and there are many challenges yet to be overcome such as optimizing the composition of the particles to achieve sufficient imaging sensitivity without reducing therapeutic efficacy, or optimizing the surface density of treatment and targeting molecules to maintain sufficient specificity and therapeutic ability [110].

Despite the incredible promise and capabilities of nanomaterial contrast agents, there are still many challenges that need to be overcome before they can be used clinically. Some nanomaterials, such as quantum dots for example, have serious concerns related to their biodegradability and toxicity, despite their excellent performance [114]. Compared to conventional small-molecule contrast agents, nanoparticles can experience significant bio-accumulation resulting from an inability to be cleared via either renal filtration or undergo

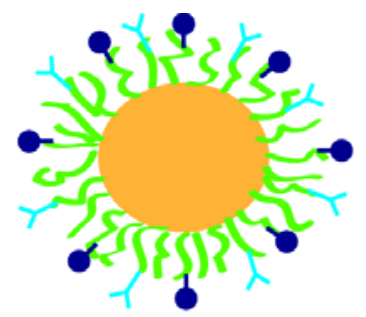

Iron Oxide Core, Gold Core, or Quantum Dot

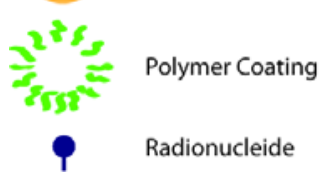

Figure 5: Drawing showing an example of potential multimodal imaging contrast agents combining a PET radiotracer with a fluorescent (Quantum Dot), X-ray adsorbing (Gold), or MRI contrast agent (iron oxide) core. bio-degradation processes [14,107]. This raises concerns about cytotoxic effects as the long-term exposure can lead to oxidative damage or chronic inflammation [107]. Furthermore, certain nanoparticle formulations are worrisome due to the known or suspected toxicity of their breakdown products. Quantum dots for example contain cadmium, which is cytotoxic; thus cadmium that is released either acutely through particle degradation or chronically through slow-leaching of accumulated quantum dots is a serious concern $[14,107,115]$. In general the toxicity of many nanomaterials is poorly understood, and this will continue to prevent their wide-spread adoption until these questions are answered [114,116]. As described previously, the interactions between nanoparticles and biological media are complex and influenced by many factors, some of which are still poorly understood. Thus more work needs to be done to characterize and control these interactions to produce nanoparticles with desired pharmacokinetic and degradation profiles [117]. Furthermore, much of the chemistry used to produce and functionalize nanoparticles needs to be optimized and refined in order to produce consistent and reliable products suitable for clinical use. Active targeting technologies in particular, while proving quite successful in the lab, face many challenges in terms of reproducible and cost-effective synthesis [118]. More work still needs to be done to develop scalable and repeatable synthesis technologies. Another important area of study for effective commercialization of nanotechnologies is to characterize their stability during storage. Nanoparticles are considered to be a high-energy state due to their large surface-area to volume ratio. While this is a desirable property in the sense that it provides ample opportunity for novel functionalization and material manipulation, it also requires the development of effective stabilization schemes to prevent particle aggregation during storage.

Further complicating all of these concerns is a general lack of literature data on the safety and efficacy of nanomaterials in humans. In 2006 the US Food and Drug Administration (FDA) acknowledged the impact that engineered nanomaterials will have in future clinical products, and formed a task force to examine specific regulatory issues related to nanotechnology $[116,117]$. Currently the FDA has developed a specific definition to determine which new pharmaceutical agents are to be called nanomaterials; however the regulatory and approval process has not been modified, and questions still remain as to whether the traditional criteria are sufficient or directly applicable to nanomaterials [119]. As more engineered nanomaterials enter into clinical trials, many of these regulatory concerns will be examined and hopefully conclusions can be reached that will expedite future development and testing of engineered nanomaterials. Table 2 summarizes the main advantages and disadvantages/challenges associated with nanomaterial based contrast agents.

Despite a few notable commercial successes, many of the nanoparticle systems described in this paper are still in primary development or pre-clinical phases, as well as a few clinical trials. This is largely due to the complications and challenges mentioned above, as well as the fact that many of these agents in their current forms simply do not provide enough added benefit to justify taking them through the long process of clinical implementation. At this time many current medical nanotechnologies are best referred to as immature; they have good ideas at their core that show promising and useful characteristics, yet in their current form they are not able to realize them to their full potential. Over the years to come, we expect there to be a maturation of these technologies, a process that will involve fine-tuning our current technologies through the integration of many different lines of research. Thus in our view, a mature nanotechnology contrast agent is one which 
Citation: Rosen JE, Yoffe S, Meerasa A, Verma M, Gu FX (2011) Nanotechnology and Diagnostic Imaging: New Advances in Contrast Agent Technology. J Nanomedic Nanotechnol 2:115. doi:10.4172/2157-7439.1000115

Page 8 of 12

\begin{tabular}{|c|c|c|c|c|c|}
\hline Imaging Type & Base Contrast Material & Specific Types & Current Status & $\begin{array}{l}\text { Active Compound (trade } \\
\text { name) of Some Clinically } \\
\text { Approved Agents }\end{array}$ & References \\
\hline \multirow[t]{3}{*}{ MRI } & Gadolinium Chelates and Salts & & Clinical use & $\begin{array}{l}\text { gadofosveset trisodium } \\
\text { (ABLAVAR); gadoxetate } \\
\text { disodium (EOVIST); } \\
\text { gadobutrol (Gadavist); } \\
\text { gadopentetate dimeglumine } \\
\text { (MAGNEVIST®); } \\
\text { gadobenate dimeglumine } \\
\text { (MultiHance); gadodiamide } \\
\text { (OMNISCAN); } \\
\text { gadoversetamide } \\
\text { (OptiMARK }{ }^{T M} \text { ); gadoteridol } \\
\text { (ProHance) }\end{array}$ & {$[60,60-64]$} \\
\hline & Gadolinium Nanostructures & $\begin{array}{l}\text { Polymers, } \\
\text { liposomes, inorganic } \\
\text { nanoparticles }\end{array}$ & Pre-clinical & - & {$[63,65-68,68,69]$} \\
\hline & Iron Oxide Nanoparticles & $\begin{array}{l}\text { Polymer-coated iron } \\
\text { oxide nanoparticles }\end{array}$ & $\begin{array}{l}\text { Clinical use and } \\
\text { some clinical trials }\end{array}$ & $\begin{array}{l}\text { ferumoxsil (GastroMARK®, } \\
\left.\text { Lumirem }^{\circledR}\right) ; \text { ferrixan } \\
\left.\text { (Resovist }^{\circledR}, \text { Cliavist }^{T M}\right) \text {; } \\
\text { ferumoxide }(\text { Feridex } \\
\text { Endorem }\end{array}$ & {$[23,44,59,70-74]$} \\
\hline \multirow{7}{*}{ CT } & \multirow{4}{*}{ Conventional lodine } & High-osmolarity & Clinical use & $\begin{array}{l}\text { diatrizoate anion } \\
\text { (Renografin); diatrizoate } \\
\text { anion (Hypaque); } \\
\text { iothalamate anion (Conray) }\end{array}$ & \multirow{4}{*}{ [83] } \\
\hline & & Nonionic monomers & Clinical use & $\begin{array}{l}\text { iohexol (Omnipaque); } \\
\text { iopamidol (Isovue); ioversol } \\
\text { (Optiray); iopromide } \\
\text { (Ultravist) }\end{array}$ & \\
\hline & & Ionic dimers & Clinical use & ioxaglate (Hexabrix) & \\
\hline & & Nonionic dimers & Clinical use & $\begin{array}{l}\text { iotrol and iodixanol } \\
\text { (Visipaque) }\end{array}$ & \\
\hline & Bismuth sulphide $\left(\mathrm{Bi}_{2} \mathrm{~S}_{3}\right)$ nanoparticles & - & Pre-clinical & - & [75] \\
\hline & lodinated nanostructure & $\begin{array}{l}\text { Polymeric } \\
\text { carriers, liposomal } \\
\text { carriers, inorganic } \\
\text { nanostructures }\end{array}$ & Pre-clinical & - & [78-90] \\
\hline & Gold nanoparticles & & Clinical trials & - & {$[76,77]$} \\
\hline \multirow[t]{2}{*}{ PET/SPECT } & $\begin{array}{l}\text { Radiopharmaceuticals: Labeled } \\
\text { biomolecules or elemental emitters }\end{array}$ & Labelled biomolecule & $\begin{array}{l}\text { Clinical use and } \\
\text { pre-clinical }\end{array}$ & $\begin{array}{l}\text { FLUDEOXYGLUCOSE } \\
\text { F-18; AdreView } \\
\text { (lobenguane I } 123 \\
\text { Injection); DaTscan } \\
\text { loflupane I } 123 \text { Injection; } \\
\text { F-18; I-123; O-15; N-13; } \\
\text { C-11 L-methionine; }\end{array}$ & [120] \\
\hline & Nanostructures with radionuclides & & Pre-clinical & & {$[90,92,93]$} \\
\hline \multirow{3}{*}{$\begin{array}{l}\text { Fluorescence/Optical } \\
\text { Imaging }\end{array}$} & Fluorescent silica particles & & Pre-clinical & & {$[102,104-106]$} \\
\hline & Quantum dots & & Pre-clinical & & {$[14,95,97-101]$} \\
\hline & Polymer encapsulated fluorophores & & Pre-clinical & & {$[102,103]$} \\
\hline
\end{tabular}

Table 1: Summary of the various types of contrast media in clinical use or pre-clinical development for various imaging techniques.

combines the inherent material advantages of a new agent (e.g. gold nanoparticles), with optimized stealth coatings, further functionalized with effective targeting ligands. These new materials will truly embrace the concept of multi-modality and theranostics, integrating advances in various fields to create products with significant clinical advantages. All of these aspects will come together through simplified and scalable synthesis methods, which allow for the efficient production on a clinically relevant scale. Finally, a mature nanotechnology must be manufactured in a repeatable and efficient way, which encompasses effective purification and quality control measures to ensure product uniformity. Over the next few years, we expect that a broader and more complete picture of the way that nanomaterials interact with the body will begin to emerge. Advancements in our understanding of the immunologic interactions of nanomaterials will lead to the development of new materials with desired pharmacokinetic profiles and enhanced biocompatibility. More detailed characterization of the toxocologic effects of nanomaterials and their breakdown products will advance our understanding of how to create safe materials that can be safely employed in clinical settings. These advancements will not only enhance our ability to design effective nanomaterials for biomedical applications, but will also give regulator bodies and the public at large the confidence to allow nanomaterials to enter wider clinical use. The opening of these roadblocks will hopefully foster renewed corporate and scientific effort in the development of nanomaterials due to their 
Citation: Rosen JE, Yoffe S, Meerasa A, Verma M, Gu FX (2011) Nanotechnology and Diagnostic Imaging: New Advances in Contrast Agent Technology. J Nanomedic Nanotechnol 2:115. doi:10.4172/2157-7439.1000115

Page 9 of 12

\begin{tabular}{|c|c|}
\hline Advantages & Disadvantages/Challenges \\
\hline $\begin{array}{l}\text { - New classes of materials allow for diversity (e.g. iron oxide instead } \\
\text { of gadolinium) } \\
\text { - New imaging modalities (e.g. fluorescence) possible } \\
\text { - } \text { Multimodal imaging } \\
\text { - } \quad \text { Theranostics } \\
\text { - Longer over tissue distribution (i.e. targeting) } \\
\text { design parameters }\end{array}$ & $\begin{array}{l}\text { - Poorly understood interactions between nanomaterials and biological systems } \\
\text { - Challenges in scale-up to consistent large-scale manufacturing } \\
\text { - } \text { Poncerns regarding materials stability during storage (e.g. aggregation, degradation) } \\
\text { particles } \\
\text { - Potential for toxic breakdown products (e.g. Cd from CdSe quantum dots); study of nano- } \\
\text { toxicology is quite complex } \\
\text { - Regulatory barriers }\end{array}$ \\
\hline
\end{tabular}

Table 2: Overview of main advantages and disadvantages of nanotechnology-based contrast agents.

greater commercialization potential. By integrating our advances across these wide-ranging fields, mature nanotechnologies will begin to emerge with real impact on clinical diagnostics and therapeutics.

\section{Conclusion}

The rapidly expanding use of diagnostic imaging technologies continues to push the boundaries of our diagnostic capabilities. Using these techniques, doctors are able to diagnose diseases earlier and more precisely, and obtain a variety of structural and functional information about the body. Contrast agents are a key part of these techniques, allowing allowing us to obtain even greater detail and sensitivity in diagnostic images. In order to continue to drive the growth in capabilities of diagnostic imaging technologies it is critical that new and enhanced contrast agents be developed to overcome the various problems associated with traditional materials and to further enhance the capability and specificity of these techniques. Nanotechnology offers us the opportunity to precisely tune and control the chemical and physical properties of contrast materials in order to overcome concerns with toxicity, useful imaging time, tissue specificity, and signal strength. In order to design efficient and effective nanomaterial contrast agents, it is crucial to have an understanding of the various biological interactions that the particles will encounter. Through the precise control of particle size and surface properties, we can engineer the pharmacokinetic profiles of these nanomaterials. By incorporating active and passive targeting techniques we can improve the accuracy of our imaging techniques, allowing for earlier diagnosis and treatment of life-threatening conditions such as cancer. Furthermore nanomaterials allow us to combine many different functional materials into a single package, creating multimodal contrast agents capable of providing simultaneous structural and functional information about the body. Thus progress in the field of nano-scale contrast agents will play a key role in the continued enhancement of our diagnostic imaging capabilities in the coming years.

\section{Acknowledgements}

This work was financially supported by the National Sciences and Engineering Research Council of Canada (NSERC).

\section{References}

1. Gu FX, Karnik R, Wang AZ, Alexis F, Levy-Nissenbaum E, et al. (2007) Targeted nanoparticles for cancer therapy. Nano Today 2: 14-21.

2. Petkar KC, Chavhan SS, Agatonovik-Kustrin S, Sawant KK (2011) Nanostructured Materials in Drug and Gene Delivery: A Review of the State of the Art. Crit Rev Ther Drug Carrier Syst 28: 101-164.

3. Shi J, Votruba AR, Farokhzad OC, Langer R (2010) Nanotechnology in Drug Delivery and Tissue Engineering: From Discovery to Applications. Nano Lett 10: $3223-3230$.

4. Erickson D, Mandal S, Yang AHJ, Cordovez B (2008) Nanobiosensors: optofluidic, electrical and mechanical approaches to biomolecular detection at the nanoscale. Microfluid Nanofluid 4: 33-52.

5. Power S, Slattery MM, Lee MJ (2011) Nanotechnology and its Relationship to Interventional Radiology. Part I: Imaging. Cardiovasc Intervent Radiol 34: 221-226.

6. Weissleder R, Hahn PF, Stark DD, Elizondo G, Saini S, et al. (1988) Superparamagnetic Iron-Oxide - Enhanced Detection of Focal Splenic Tumors with Mr Imaging. Radiology 169: 399-403.

7. Meerasa A, Huang JG, Gu FX (2011) $\mathrm{CH}(50)$ : A Revisited Hemolytic Complement Consumption Assay for Evaluation of Nanoparticles and Blood Plasma Protein Interaction. Curr Drug Deliv 8: 290-298.

8. Moghimi SM, Hunter AC, Murray JC (2001) Long-circulating and target-specific nanoparticles: theory to practice. Pharmacol Rev 53: 283-318.

9. Vega-Villa KR, Takemoto JK, Yanez JA, Remsberg CM, Forrest ML, et al (2008) Clinical toxicities of nanocarrier systems. Adv Drug Deliv Rev 60: 929938

10. Zahr AS, Davis CA, Pishko MV (2006) Macrophage Uptake of Core-Shel Nanoparticles Surface Modified with Poly(ethylene glycol). Langmuir 22: 81788185

11. Owens DE, Peppas NA (2006) Opsonization, biodistribution, and pharmacokinetics of polymeric nanoparticles. Int J Pharm 307: 93-102.

12. Vonarbourg A, Passirani C, Saulnier P, Benoit JP (2006) Parameters influencing the stealthiness of colloidal drug delivery systems. Biomaterials 27: 4356-4373.

13. Alexis F, Farokhzad OC, Pridgen E, Molnar LK (2008) Factors Affecting the Clearance and Biodistribution of Polymeric Nanoparticles. Molecular Pharmaceutics 5: 505-515.

14. Choi HS, Liu W, Misra P, Tanaka E, Zimmer JP, et al. (2007) Renal clearance of quantum dots. Nat Biotechnol 25: 1165-1170.

15. Forge D, Roch A, Laurent S, Tellez H, Gossuin Y, et al. (2008) Optimization of the Synthesis of Superparamagnetic Contrast Agents by the Design of Experiments Method. J Phys Chem C 112: 19178-19185.

16. Park JY, Daksha P, Lee GH, Woo S, Chang Y (2008) Highly water-dispersible PEG surface modified ultra small superparamagnetic iron oxide nanoparticles useful for target-specific biomedical applications. Nanotechnology 19: 365603 365603.

17. Yu M, Jeong Y, Park J, Park S, Kim J, et al. (2008) Drug-Loaded Superparamagnetic Iron Oxide Nanoparticles for Combined Cancer Imaging and Therapy In Vivo. Angew Chem Int Ed 47: 5362-5365.

18. Bajpai AK, Gupta R (2010) Synthesis and characterization of magnetite (Fe3O4)-Polyvinyl alcohol-based nanocomposites and study of superparamagnetism. Polym Compos 31: 245-255.

19. Mahmoudi M, Simchi A, Imani M, Milani AS, Stroeve P (2008) Optimal Design and Characterization of Superparamagnetic Iron Oxide Nanoparticles Coated with Polyvinyl Alcohol for Targeted Delivery and Imaging. J Phys Chem B 112 14470-14481.

20. Lin H, Watanabe $Y$, Kimura M, Hanabusa K, Shirai H (2003) Preparation of magnetic poly(vinyl alcohol) (PVA) materials by in situ synthesis of magnetite in a PVA matrix. J Appl Polym Sci 87: 1239-1247.

21. Babic M, Horak D, Trchova M, Jendelova P, Glogarova K, et al. (2008) Poly(L lysine)-modified iron oxide nanoparticles for stem cell labeling. Bioconjug Chem 19: 740-750.

22. Santra S, Kaittanis C, Grimm J, Perez JM (2009) Drug/Dye-Loaded Multifunctional Iron Oxide Nanoparticles for Combined Targeted Cance Therapy and Dual Optical/Magnetic Resonance Imaging. Small 5: 1862-1868.

23. Qiao R, Yang C, Gao M (2009) Superparamagnetic iron oxide nanoparticles: from preparations to in vivo MRI applications. Journal of Materials Chemistry 19: 6274-6293. 
Citation: Rosen JE, Yoffe S, Meerasa A, Verma M, Gu FX (2011) Nanotechnology and Diagnostic Imaging: New Advances in Contrast Agent Technology. J Nanomedic Nanotechnol 2:115. doi:10.4172/2157-7439.1000115

24. Sirlin CB, Vera DR, Corbeil JA, Caballero MB, Buxton RB, et al. (2004) Gadolinium-DTPA-dextran: A macromolecular MR blood pool contrast agent ${ }^{1}$. Acad Radiol 11: 1361-1369.

25. Hifumi H, Yamaoka S, Tanimoto A, Akatsu T, Shindo Y, et al. (2009) Dextran Coated Gadolinium Phosphate Nanoparticles for Magnetic Resonance Tumor Imaging. J Mater Chem 19: 6393-6399.

26. Earhart C, Erathodiyil N, Jana NR, Ying JY (2008) Synthesis of CarbohydrateConjugated Nanoparticles and Quantum Dots. Langmuir 24: 6215-6219.

27. Hong RY, Li JH, Qu JM, Chen LL, Li HZ (2009) Preparation and characterization of magnetite/dextran nanocomposite used as a precursor of magnetic fluid. Chem Eng J 150: 572-580.

28. Ma H, Xu Y, Qi X, Maitani Y, Nagai T (2008) Superparamagnetic iron oxide nanoparticles stabilized by alginate: Pharmacokinetics, tissue distribution, and applications in detecting liver cancers. Int J Pharm 354: 217-226.

29. Grant GT, Morris ER, Rees DA, Smith PJC, Thom D (1973) Biological Interactions between Polysaccharides and Divalent Cations - Egg-Box Model. FEBS Lett 32: 195-198.

30. Gombotz W, Wee S (1998) Protein release from alginate matrices. Adv Drug Deliv Rev 31: 267-285.

31. Lopez-Cruz A., Barrera C., Calero-DdelC V.L., Rinaldi C. (2009) Water dispersible iron oxide nanoparticles coated with covalently linked chitosan. $J$ Mater Chem 19: 6870-6876.

32. Tsai Z, Wang J, Kuo H, Shen C, Wang J, et al. (2010) In situ preparation of high relaxivity iron oxide nanoparticles by coating with chitosan: A potential MRI contrast agent useful for cell tracking. J Magn Magn Mater 322: 208-213.

33. Lee H, Shao H, Huang Y, Kwak B (2005) Synthesis of MRI contrast agen by coating superparamagnetic iron oxide with chitosan. Magnetics, IEEE Transactions on 41: 4102-4104.

34. Kim DK, Mikhaylova M, Wang FH, Kehr J, Bjelke B, et al. (2003) Starch-Coated Superparamagnetic Nanoparticles as MR Contrast Agents. Chem Mater 15: 4343-4351.

35. Saboktakin MR, Maharramov A, Ramazanov MA (2009) Synthesis and characterization of superparamagnetic nanoparticles coated with carboxymethyl starch (CMS) for magnetic resonance imaging technique. Carbohydr Polym 78: 292-295.

36. Jiang J, Gan Z, Yang Y, Du B, Qian M, et al. (2009) A novel magnetic fluid based on starch-coated magnetite nanoparticles functionalized with homing peptide. Journal of Nanoparticle Research 11: 1321-1330.

37. Kattumuri V, Katti K, Bhaskaran S, Boote E, Casteel S, et al. (2007) Gum Arabic as a Phytochemical Construct for the Stabilization of Gold Nanoparticles: In Vivo Pharmacokinetics and X-ray-Contrast-Imaging Studies. Small 3: 333341.

38. Williams DN, Gold KA, Holoman TRP, Ehrman SH, Wilson OC (2006) Surface Modification of Magnetic Nanoparticles Using Gum Arabic. J Nanopart Res 8 : 749-753.

39. Zhang L, Yu FQ, Cole AJ, Chertok B, David AE, et al (2009) Gum ArabicCoated Magnetic Nanoparticles for Potential Application in Simultaneous Magnetic Targeting and Tumor Imaging. AAPS J 11: 693-699.

40. Rosen J, Gu F (2011) Surface functionalization of silica nanoparticles with cysteine: a low-fouling zwitterionic surface. Langmuir 27: 10507-10513.

41. Maeda H, Wu J, Sawa T, Matsumura Y, Hori K (2000) Tumor vascula permeability and the EPR effect in macromolecular therapeutics: a review. J Control Release 65: 271-284

42. Noguchi Y, Wu J, Duncan R, Strohalm J, Ulbrich K, et al. (1998) Early phase tumor accumulation of macromolecules: a great difference in clearance rate between tumor and normal tissues. Jap J Cancer Res 89: 307-314.

43. Brannon-Peppas L, Blanchette JO (2004) Nanoparticle and targeted systems for cancer therapy. Adv Drug Deliv Rev 56: 1649-1659.

44. Laurent S, Forge D, Port M, Roch A, Robic C, et al. (2008) Magnetic iron oxide nanoparticles: Synthesis, stabilization, vectorization, physicochemical characterizations, and biological applications. Chem Rev 108: 2064-2110.

45. Zhang C, Jugold M, Woenne EC, Lammers T, Morgenstern B, et al. (2007) Specific targeting of tumor angiogenesis by RGD-conjugated ultrasmal superparamagnetic iron oxide particles using a clinical 1.5-T magnetic resonance scanner. Cancer Res 67: 1555-1562.
46. Sonvico F, Mornet S, Vasseur S, Dubernet C, Jaillard D, et al. (2005) Folateconjugated iron oxide nanoparticles for solid tumor targeting as potentia specific magnetic hyperthermia mediators: Synthesis, physicochemica characterization, and in vitro experiments. Bioconjug Chem 16: 1181-1188.

47. Allen TM (2002) Ligand-targeted therapeutics in anticancer therapy. Nat Rev Cancer 2: 750-763

48. Chen T, Cheng T, Hung Y, Lin K, Liu G, et al. (2008) Targeted folic acid-PEG nanoparticles for noninvasive imaging of folate receptor by MRI. J Biomed Mater Res Part A 87A: 165-175.

49. Fan C, Gao W, Chen Z, Fan H, Lie M, et al. (2011) Tumor selectivity of stealth multi-functionalized superparamagnetic iron oxide nanoparticles. Int J Pharm 404: 180-190.

50. Weissleder R, Lee A, Khaw B, Shen T, Brady T (1992) Antimyosin-Labeled Monocrystalline Iron-Oxide Allows Detection of Myocardial Infarct - Mr Antibody Imaging. Radiology 182: 381-385

51. Kang H, Josephson L, Petrovsky A, Weissleder R, Bogdanov A (2002) Magnetic resonance imaging of inducible E-selectin expression in human endothelial cell culture. Bioconjug Chem 13: 122-127.

52. Islam T, Josephson $L$ (2009) Current state and future applications of active targeting in malignancies using superparamagnetic iron oxide nanoparticles. Cancer Biomark 5: 99-107.

53. Iyer AK, Khaled G, Fang J, Maeda H (2006) Exploiting the enhanced permeability and retention effect for tumor targeting. Drug Discov Today 11 812-818.

54. Rosen JE, Chan L, Shieh DB, Gu FX (2011) Iron oxide nanoparticles for targeted cancer imaging and diagnostics. Nanomedicine.

55. Banerjee SS, Chen D (2008) Multifunctional $\mathrm{P}^{\mathrm{H}}$-sensitive magnetic nanoparticles for simultaneous imaging, sensing and targeted intracellular anticancer drug delivery. Nanotechnology 19: 1-8.

56. Jain TK, Richey J, Strand M, Leslie-Pelecky DL, Flask CA, et al. (2008) Magnetic nanoparticles with dual functional properties: Drug delivery and magnetic resonance imaging. Biomaterials 29: 4012-4021.

57. Smirnov P, Poirier-Quinot M, Wilhelm C, Lavergne E, Ginefri J, et al. (2008) In vivo single cell detection of tumor-infiltrating lymphocytes with a clinical 1.5 Tesla MRI system. Magn Reson Med 60: 1292-1297.

58. Shapiro EM, Sharer K, Skrtic S, Koretsky AP (2006) In vivo detection of single cells by MRI. Magn Reson Med 55: 242-249.

59. Shapiro EM, Skrtic S, Sharer K, Hill JM, Dunbar CE, et al. (2004) MRI detection of single particles for cellular imaging. Proc Natl Acad Sci U S A 101: 10901 10906.

60. Zhu D, White RD, Hardy PA, Weerapreeyakul N, Sutthanut K, et al. (2006) Biocompatible Nanotemplate-Engineered Nanoparticles Containing Gadolinium: Stability and Relaxivity of a Potential MRI Contrast Agent. J Nanosci Nanotechnol 6: 996-1003.

61. Caravan P, Ellison JJ, McMurry TJ, Lauffer RB (1999) Gadolinium(III) Chelates as MRI Contrast Agents: Structure, Dynamics, and Applications. Chem Rev 99: 2293-2352.

62. Khemtong C, Kessinger CW, Gao J (2009) Polymeric nanomedicine for cance MR imaging and drug delivery. Chem Commun 3497-3510.

63. Helm L (2010) Optimization of gadolinium-based MRI contrast agents for high magnetic-field applications. Future Med Chem 2: 385-396.

64. Park J, Lee J, Jung J, Yu D, Oh C, et al. (2008) Gd-DOTA Conjugate of RGD as a Potential Tumor-Targeting MRI Contrast Agent. ChemBioChem 9: 2811 2813.

65. Zhang W, Yong D, Huang J, Yu J, Liu S, et al. (2011) Fabrication of Polymer-Gadolinium (III) Complex Nanomicelle from Poly(ethylene glycol)Polysuccinimide Conjugate and Diethylenetriaminetetraacetic Acid-Gadolinium as Magnetic Resonance Imaging Contrast Agents. J Appl Polym Sci 120: 25962605

66. Karfeld-Sulzer LS, Waters EA, Davis NE, Meade TJ, Barron AE (2010) Multivalent Protein Polymer MRI Contrast Agents: Controlling Relaxivity via Modulation of Amino Acid Sequence. Biomacromolecules 11: 1429-1436.

67. Kamaly N, Miller AD (2010) Paramagnetic Liposome Nanoparticles for Cellular and Tumour Imaging. Int J Mol Sci 11: 1759-1776. 
Citation: Rosen JE, Yoffe S, Meerasa A, Verma M, Gu FX (2011) Nanotechnology and Diagnostic Imaging: New Advances in Contrast Agent Technology. J Nanomedic Nanotechnol 2:115. doi:10.4172/2157-7439.1000115

68. Na HB, Song IC, Hyeon T (2009) Inorganic Nanoparticles for MRI Contrast Agents. Adv Mater 21: 2133-2148.

69. Shao Y, Liu L, Song S, Cao R, Liu H, et al. (2011) A novel one-step synthesis of Gd3+-incorporated mesoporous $\mathrm{SiO} 2$ nanoparticles for use as an efficient MR contrast agent. Contrast Media Mol Imaging 6: 110-118.

70. Teja AS, Koh P (2009) Synthesis, properties, and applications of magnetic iron oxide nanoparticles. Prog Cryst Growth Charact Mater 55: 22-45.

71. Murbe J, Rechtenbach A, Topfer J (2008) Synthesis and physical characterization of magnetite nanoparticles for biomedical applications. Materials Chemistry \& Physics 110: 426-433

72. Sun C, Lee JSH, Zhang M (2008) Magnetic nanoparticles in MR imaging and drug delivery. Adv Drug Deliv Rev 60: 1252-1265.

73. Hong J, Gong P, Xu D, Sun H, Yao S (2007) Synthesis and characterization of carboxyl functionalized magnetic nanogel via "green" photochemical method. J Appl Polym Sci 105: 1882-1887

74. Gupta AK, Gupta M (2005) Synthesis and surface engineering of iron oxide nanoparticles for biomedical applications. Biomaterials 26: 3995-4021.

75. Rabin O, Perez JM, Grimm J, Wojtkiewicz G, Weissleder R (2006) An X-ray computed tomography imaging agent based on long-circulating bismuth sulphide nanoparticles. Nat Mater 5: 118-122.

76. Hainfeld JF, Slatkin DN, Focella TM, Smilowitz HM (2006) Gold nanoparticles: a new X-ray contrast agent. Br J Radiol 79: 248-253.

77. Kim D, Park S, Lee JH, Jeong YY, Jon S (2007) Antibiofouling polymer-coated gold nanoparticles as a contrast agent for in vivo $\mathrm{x}$-ray computed tomography imaging. J Am Chem Soc 129: 7661-7665.

78. deKrafft KE, Xie Z, Cao G, Tran S, Ma L, et al. (2009) lodinated Nanoscale Coordination Polymers as Potential Contrast Agents for Computed Tomography. Angew Chem Int Edit 48: 9901-9904

79. Mukundan S, Ghaghada KB, Badea CT, Kao CY, Hedlund LW, et al. (2006) A liposomal nanoscale contrast agent for preclinical CT in mice. Am J Roentgenol 186: 300-307.

80. Pan D, Williams TA, Senpan A, Allen JS, Scott MJ, et al. (2009) Detecting Vascular Biosignatures with a Colloidal, Radio-Opaque Polymeric Nanoparticle. J Am Chem Soc 131: 15522-15527.

81. Hyafil F, Cornily J, Feig JE, Gordon R, Vucic E, et al. (2007) Noninvasive detection of macrophages using a nanoparticulate contrast agent for computed tomography. Nat Med 13: 636-641.

82. Galperin A, Margel D, Baniel J, Dank G, Biton H, et al. (2007) Radiopaque iodinated polymeric nanoparticles for X-ray imaging applications. Biomaterials 28: $4461-4468$

83. Hahn MA, Singh AK, Sharma P, Brown SC, Moudgil BM (2011) Nanoparticles as contrast agents for in-vivo bioimaging: current status and future perspectives. Anal Bioanal Chem 399: 3-27.

84. Elrod DB, Partha R, Danila D, Casscells SW, Conyers JL (2009) An iodinated liposomal computed tomographic contrast agent prepared from a diiodophosphatidylcholine lipid. Nanomedicine 5: 42-45.

85. Kweon S, Lee H, Hyung WJ, Suh J, Lim JS, et al. (2010) Liposomes Coloaded with lopamidol/Lipiodol as a RES-Targeted Contrast Agent for Computed Tomography Imaging. Pharm Res 27: 1408-1415.

86. Zheng J, Allen C, Serra S, Vines D, Charron M, et al. (2010) Liposome contrast agent for CT-based detection and localization of neoplastic and inflammatory lesions in rabbits: validation with FDG-PET and histology. Contrast Media Mol Imaging 5: 147-154.

87. Chrastina A, Schnitzer JE (2010) lodine-125 radiolabeling of silver nanoparticles for in vivo SPECT imaging. Int J Nanomed 5: 653-659.

88. Van Herck JL, De Meyer GRY, Martinet W, Salgado RA, Shivalkar B, et al. (2010) Multi-slice computed tomography with N1177 identifies ruptured atherosclerotic plaques in rabbits. Basic Res Cardiol 105: 51-59.

89. Aillon KL, El-Gendy N, Dennis C, Norenberg JP, McDonald J, et al. (2010) lodinated Nano Clusters as an Inhaled Computed Tomography Contrast Agent for Lung Visualization. Mol Pharm 7: 1274-1282.

90. Cai W, Chen X (2007) Nanoplatforms for targeted molecular imaging in living subjects. Small 3: 1840-1854.
91. Herth MM, Barz M, Moderegger D, Allmeroth M, Jahn M, et al. (2009) Radioactive Labeling of Defined HPMA-Based Polymeric Structures Using [F-18]FETos for In Vivo Imaging by Positron Emission Tomography. Biomacromolecules 10 : 1697-1703.

92. Hong H, Zhang Y, Sun J, Cai W (2009) Molecular imaging and therapy of cancer with radiolabeled nanoparticles. Nano Today 4: 399-413.

93. Liu Z, Cai W, He L, Nakayama N, Chen K, et al. (2007) In vivo biodistribution and highly efficient tumour targeting of carbon nanotubes in mice. Nat Nanotechnol 2: 47-52.

94. Nune SK, Gunda P, Thallapally PK, Lin Y, Forrest ML, et al. (2009) Nanoparticles for biomedical imaging. Expert Opin Drug Deliv 6: 1175-1194.

95. Smith AM, Dave S, Nie SM, True L, Gao XH (2006) Multicolor quantum dots for molecular diagnostics of cancer. Expert Rev Mol Diagn 6: 231-244.

96. Pan J, Wang Y, Feng S (2008) Formulation, characterization, and in vitro evaluation of quantum dots loaded in poly(lactide)-vitamin E TPGS nanoparticles for cellular and molecular imaging. Biotechnol Bioeng 101: 622 633.

97. Cai W, Hsu AR, Li ZB, Chen X (2007) Are quantum dots ready for in vivo imaging in human subjects? Nanoscale Res Lett 2: 265-281.

98. Gao XH, Cui YY, Levenson RM, Chung LW, Nie S (2004) In vivo cancer targeting and imaging with semiconductor quantum dots. Nat Biotechnol 22 969-976.

99. Yang L, Mao H, Wang YA, Cao Z, Peng X, et al. (2009) Single Chain Epidermal Growth Factor Receptor Antibody Conjugated Nanoparticles for in vivo Tumor Targeting and Imaging. Small 5: 235-243.

100. Ballou B, Ernst LA, Waggoner AS (2005) Fluorescence imaging of tumors in vivo. Curr Med Chem 12: 795-805.

101. Ballou B, Ernst LA, Andreko S, Harper T, Fitzpatrick JAJ, et al. (2007) Sentinel Lymph Node Imaging Using Quantum Dots in Mouse Tumor Models. Bioconjug Chem 18: 389-396.

102. Wang L, Wang K, Santra S, Zhao X, Hilliard LR, et al. (2006) Watching Silica Nanoparticles Glow in the Biological World. Anal Chem 78: 646-654.

103. Yan J, Estevez MC, Smith JE, Wang K, He X, et al. (2007) Dye-doped nanoparticles for bioanalysis. Nano Today 2: 44-50.

104. Ow H, Larson DR, Srivastava M, Baird BA, Webb WW, et al. (2005) Brigh and stable core-shell fluorescent silica nanoparticles. Nano Lett 5: 113-117.

105. Choi J, Burns AA, Williams RM, Zhou Z, Flesken-Nikitin A, et al. (2007) Coreshell silica nanoparticles as fluorescent labels for nanomedicine. J Biomed Opt 12: 064007

106. Burns AA, Vider J, Ow H, Herz E, Penate-Medina O, et al. (2009) Fluorescent Silica Nanoparticles with Efficient Urinary Excretion for Nanomedicine. Nano Lett 9: 442-448.

107. Minchin RF, Martin DJ (2010) Nanoparticles for Molecular Imaging-An Overview. Endocrinology 151: 474-481.

108. Abu-Alfa AK (2011) Nephrogenic Systemic Fibrosis and Gadolinium-Based Contrast Agents. Adv Chronic Kidney Dis 18: 188-198.

109. Chen XS (2011) Introducing Theranostics Journal - From the Editor-in-Chief Theranostics 1: 1-2

110. Janib SM, Moses AS, MacKay JA (2010) Imaging and drug delivery using theranostic nanoparticles. Adv Drug Deliv Rev 62: 1052-1063.

111. Gianella A, Jarzyna PA, Mani V, Ramachandran S, Calcagno C, et al. (2011) Multifunctional Nanoemulsion Platform for Imaging Guided Therapy Evaluated in Experimental Cancer. ACS Nano 5: 4422-4433.

112. Cheng Y, Meyers JD, Broome A, Kenney ME, Basilion JP, et al. (2011) Deep Penetration of a PDT Drug into Tumors by Noncovalent Drug-Gold Nanoparticle Conjugates. J Am Chem Soc 133: 2583-2591.

113. Cole AJ, Yang VC, David AE (2011) Cancer theranostics: the rise of targeted magnetic nanoparticles. Trends Biotechnol 29: 323-332.

114. Murthy SK (2007) Nanoparticles in modern medicine: State of the art and future challenges. Int J Nanomedicine 2: 129-141. 
Citation: Rosen JE, Yoffe S, Meerasa A, Verma M, Gu FX (2011) Nanotechnology and Diagnostic Imaging: New Advances in Contrast Agent Technology. J Nanomedic Nanotechnol 2:115. doi:10.4172/2157-7439.1000115

115. Rzigalinski BA, Strobl JS (2009) Cadmium-containing nanoparticles: Perspectives on pharmacology and toxicology of quantum dots. Toxicol Appl Pharmacol 238: 280-288.

116. Zolnik BS, Sadrieh N (2009) Regulatory perspective on the importance of ADME assessment of nanoscale material containing drugs. Adv Drug Deliv Rev 61: 422-427.

117. Sanhai WR, Sakamoto JH, Canady R, Ferrari M (2008) Seven challenges for nanomedicine. Nat Nanotechnol 3: 242-244.
118. Shi J, Votruba AR, Farokhzad OC, Langer R (2010) Nanotechnology in Drug Delivery and Tissue Engineering: From Discovery to Applications. Nano Lett 10: $3223-3230$.

119. Choi HS, Frangioni JV (2010) Nanoparticles for Biomedical Imaging: Fundamentals of Clinical Translation. Mol Imaging 9: 291-310.

120. Kracht L, Miletic H, Busch S, Jacobs A, Voges J, et al. (2004) Delineation of brain tumor extent with [C-11]L-methionine positron emission tomography: Local comparison with stereotactic histopathology. Clin Cancer Res 10: 7163 7170 . 